\title{
Susceptibility to Exacerbation in Chronic Obstructive Pulmonary Disease
}

\author{
John R. Hurst, M.B., Ch.B., Ph.D., Jørgen Vestbo, M.D., Antonio Anzueto, M.D., \\ Nicholas Locantore, Ph.D., Hana Müllerova, Ph.D., Ruth Tal-Singer, Ph.D., \\ Bruce Miller, Ph.D., David A. Lomas, Ph.D., Alvar Agusti, M.D., Ph.D., \\ William MacNee, M.B., Ch.B., M.D., Peter Calverley, M.D., \\ Stephen Rennard, M.D., Emiel F.M. Wouters, M.D., Ph.D. \\ and Jadwiga A. Wedzicha, M.D., for the Evaluation of COPD Longitudinally \\ to Identify Predictive Surrogate Endpoints (ECLIPSE) Investigators*
}

ABSTRACT

From the Academic Unit of Respiratory Medicine, Royal Free Campus, UCL Medical School, London (J.R.H., J.A.W.); Cardiology and Respiratory Medicine, Hvidovre Hospital and University of Copenhagen, Copenhagen (J.V.); the Respiratory Research Group, School of Translational Medicine, Manchester Academic Health Science Centre, University of Manchester, Manchester (J.V.), the Department of Medicine, University of Cambridge, Cambridge Institute for Medical Research, Cambridge (D.A.L.), and the Department of Respiratory Medicine, School of Clinical Science, University of Liverpool, Liverpool (P.C.) all in the United Kingdom; the Pulmonary Section, University of Texas Health Science Center, San Antonio (A. Anzueto); GlaxoSmithKline, Research Triangle Park, NC (N.L.), London (H.M.), and King of Prussia, PA (R.T.-S., B.M.); Institut del Tòrax, Hospital Clínic, CIBER Enfermedades Respiratorias and Fundación CaubetCimera, Barcelona (A. Agusti); ELEGI Colt Research Labs, University of Edinburgh/ MRC Centre for Inflammation Research, Queen's Medical Research Institute, Edinburgh (W.M.); the Department of Pulmonary and Critical Care Medicine, Nebraska Medical Center, Omaha (S.R.); and the Department of Respiratory Medicine, Maastricht University Medical Center, Maastricht, the Netherlands (E.F.M.W.). Address reprint requests to Dr. Vestbo at the Department of Cardiology and Respiratory Medicine 253, Hvidovre Hospital, Kettegaard Alle 30, 2650 Hvidovre, Denmark, or at jorgen.vestbo@manchester.ac.uk.

*Members of the ECLIPSE steering and scientific committees and the study investigators are listed in the Appendix.

N Engl J Med 2010;363:1128-38.

Copyright ( 2010 Massachusetts Medical Society.
BACKGROUND

Although we know that exacerbations are key events in chronic obstructive pulmonary disease (COPD), our understanding of their frequency, determinants, and effects is incomplete. In a large observational cohort, we tested the hypothesis that there is a frequent-exacerbation phenotype of COPD that is independent of disease severity.

\section{METHODS}

We analyzed the frequency and associations of exacerbation in 2138 patients enrolled in the Evaluation of COPD Longitudinally to Identify Predictive Surrogate Endpoints (ECLIPSE) study. Exacerbations were defined as events that led a care provider to prescribe antibiotics or corticosteroids (or both) or that led to hospitalization (severe exacerbations). Exacerbation frequency was observed over a period of 3 years.

\section{RESULTS}

Exacerbations became more frequent (and more severe) as the severity of COPD increased; exacerbation rates in the first year of follow-up were 0.85 per person for patients with stage 2 COPD (with stage defined in accordance with Global Initiative for Chronic Obstructive Lung Disease [GOLD] stages), 1.34 for patients with stage 3 , and 2.00 for patients with stage 4 . Overall, $22 \%$ of patients with stage 2 disease, $33 \%$ with stage 3 , and $47 \%$ with stage 4 had frequent exacerbations (two or more in the first year of follow-up). The single best predictor of exacerbations, across all GOLD stages, was a history of exacerbations. The frequent-exacerbation phenotype appeared to be relatively stable over a period of 3 years and could be predicted on the basis of the patient's recall of previous treated events. In addition to its association with more severe disease and prior exacerbations, the phenotype was independently associated with a history of gastroesophageal reflux or heartburn, poorer quality of life, and elevated white-cell count.

\section{CONCLUSIONS}

Although exacerbations become more frequent and more severe as COPD progresses, the rate at which they occur appears to reflect an independent susceptibility phenotype. This has implications for the targeting of exacerbation-prevention strategies across the spectrum of disease severity. (Funded by GlaxoSmithKline; ClinicalTrials .gov number, NCT00292552.) 
T HE NATURAL HISTORY OF CHRONIC OBstructive pulmonary disease (COPD) is punctuated by exacerbations - acute worsening of symptoms. Exacerbations appear to accelerate the decline in lung function that characterizes COPD, ${ }^{1,2}$ resulting in reduced physical activity, ${ }^{3}$ poorer quality of life ${ }^{4}$ and an increased risk of death, ${ }^{5}$ and they are also responsible for a large proportion of the health care costs attributable to this prevalent condition. ${ }^{6}$ Consequently, exacerbations are important outcomes in clinical trials, and their prevention is a key component of COPD-management strategies. ${ }^{7}$

Despite the importance of exacerbations, we know relatively little about their incidence, their determinants, and their effects in patients with COPD at various levels of severity. Although exacerbations are generally considered to become more frequent as the severity of the underlying COPD increases, the most reliable predictor of exacerbations in an individual patient appears to be a history of exacerbations. ${ }^{8}$ There may therefore be a phenotype of exacerbation susceptibility that includes milder forms of COPD. However, this theory has not been adequately investigated because our current understanding of COPD exacerbations and their relationship to disease severity is based on large intervention studies ${ }^{9,10}$ or multiple smaller studies that have used varying definitions of exacerbation. ${ }^{8}$ We used data from a large observational study to test the hypothesis that there is a frequent-exacerbation phenotype of COPD that is independent of disease severity.

\section{METHODS}

\section{STUDY DESIGN AND PATIENTS}

This analysis was based on data collected as part of the Evaluation of COPD Longitudinally to Identify Predictive Surrogate Endpoints (ECLIPSE) observational study. ${ }^{11}$ The study was conducted in accordance with the Declaration of Helsinki and Good Clinical Practice guidelines. All patients provided written informed consent, and the study was approved by the relevant ethics and review boards.

The recruitment criteria included an age of 40 to 75 years, a history of 10 or more pack-years of smoking, a forced expiratory volume in 1 second $\left(\mathrm{FEV}_{1}\right)$ of less than $80 \%$ of predicted value after bronchodilator use, and a ratio of $\mathrm{FEV}_{1}$ to forced vital capacity (FVC) of 0.7 or less after bronchodilator use.
At baseline, patients underwent standard spirometry after the administration of $400 \mu \mathrm{g}$ of inhaled albuterol. Computed tomographic (CT) scanning of the chest was performed to evaluate the severity and distribution of emphysema (for details, see the Supplementary Appendix, available with the full text of this article at NEJM.org). The condition of the patients was graded according to the stages of disease defined by the Global Initiative for Chronic Obstructive Lung Disease (GOLD). ${ }^{12}$ After the baseline visit, patients were followed for a total of seven visits: at 3 months, at 6 months, and every 6 months thereafter for 3 years.

The patients' self-reported respiratory symptoms, medications, smoking history, occupational exposure, and coexisting medical conditions were documented at study entry with the use of the wellestablished American Thoracic Society-Division of Lung Disease (ATS-DLD) questionnaire, which was updated for the purpose of this study. ${ }^{13}$

Serum and plasma samples were stored at $-80^{\circ} \mathrm{C}$ until they were analyzed. Details of the assays are described in the Supplementary Appendix. Any samples with values below the lower limit of quantification were assigned a value that was half of the lower limit.

A detailed description of methods can be found in the Supplementary Appendix. The study was conducted in accordance with the protocol, which is available at NEJM.org.

\section{STUDY OUTCOMES}

Exacerbations were a critical outcome. The case definition of an exacerbation was a functional one, based on the decision by a patient's primary clinician or by study personnel to prescribe antibiotics or systemic corticosteroids, alone or in combination. Primary clinicians were not given a specific list of criteria that had to be met for an event to be classified as an exacerbation, but they were instructed to base their decision on common clinical criteria. This case definition therefore met the criteria for a definition of health care utilization, and the exacerbations we recorded would be classified as moderate or severe in intensity. ${ }^{14}$ The case definition remained the same during the 3 years of active data accrual, and identical criteria were applied retrospectively when we collected data from patients on the number of exacerbations they had had in the year before study enrollment.

Patient-reported measures at study entry included assessments of dyspnea (made with the use of a modified Medical Research Council dyspnea 


\begin{tabular}{|c|c|c|c|c|c|}
\hline Characteristic & $\begin{array}{l}\text { All Patients } \\
(\mathrm{N}=2138)\end{array}$ & $\begin{array}{l}\text { Moderate - } \\
\text { GOLD Stage } 2 \\
\quad(\mathrm{~N}=945)\end{array}$ & $\begin{array}{c}\text { Severe - } \\
\text { GOLD Stage } 3 \\
(\mathrm{~N}=900)\end{array}$ & $\begin{array}{l}\text { Very Severe - } \\
\text { GOLD Stage } 4 \\
\quad(N=293)\end{array}$ & $P$ Value \\
\hline Age (yr) & $63 \pm 7$ & $63 \pm 7$ & $64 \pm 7$ & $62 \pm 7$ & 0.03 \\
\hline Female sex (\%) & 35 & 40 & 32 & 26 & $<0.001$ \\
\hline Current smoker (\%) & 36 & 38 & 37 & 28 & 0.016 \\
\hline Body-mass index' & $27 \pm 6$ & $27 \pm 6$ & $26 \pm 6$ & $25 \pm 6$ & $<0.001$ \\
\hline $\mathrm{FEV}_{1}$ after bronchodilator use (liters) & $1.35 \pm 0.52$ & $1.75 \pm 0.45$ & $1.13 \pm 0.27$ & $0.72 \pm 0.16$ & $<0.001$ \\
\hline $\begin{array}{l}\mathrm{FEV}_{1} \text { after bronchodilator use (\% of predicted } \\
\text { value) }\end{array}$ & $48 \pm 16$ & $63 \pm 8$ & $40 \pm 6$ & $25 \pm 4$ & $<0.001$ \\
\hline $\mathrm{FEV}_{1}: \mathrm{FVC}(\%)$ & $45 \pm 12$ & $53 \pm 9$ & $40 \pm 9$ & $32 \pm 8$ & $<0.001$ \\
\hline Distance walked in $6 \mathrm{~min}(\mathrm{~m})$ & $370 \pm 121$ & $406 \pm 112$ & $357 \pm 117$ & $290 \pm 119$ & $<0.001$ \\
\hline BODE indext & $3.2 \pm 2.1$ & $1.6 \pm 1.4$ & $4.0 \pm 1.6$ & $5.7 \pm 1.6$ & $<0.001$ \\
\hline Emphysema & & & & & $<0.001$ \\
\hline Low attenuation areas (no.) & $18 \pm 12$ & $12 \pm 10$ & $20 \pm 12$ & $28 \pm 13$ & $<0.001$ \\
\hline Extent $>5 \%$ of total area $(\%) \mathbb{S}$ & 75 & 63 & 82 & 92 & $<0.001$ \\
\hline \multicolumn{6}{|l|}{ Patient-reported outcomes } \\
\hline MRC dyspnea score $\geq 2$ (\%) & 53 & 40 & 59 & 80 & $<0.001$ \\
\hline CES depression score & $11 \pm 9$ & $11 \pm 9$ & $12 \pm 9$ & $13 \pm 10$ & 0.002 \\
\hline FACIT fatigue score & $35 \pm 11$ & $37 \pm 10$ & $34 \pm 11$ & $32 \pm 11$ & $<0.001$ \\
\hline SGRQ for COPD, total score & $50 \pm 20$ & $42 \pm 21$ & $54 \pm 18$ & $62 \pm 16$ & $<0.001$ \\
\hline \multicolumn{6}{|l|}{ Medication for COPD (\%) } \\
\hline Any long-acting bronchodilator & 76 & 67 & 83 & 86 & $<0.001$ \\
\hline Any inhaled corticosteroid & 72 & 60 & 80 & 86 & $<0.001$ \\
\hline Any methylxanthine & 14 & 9 & 16 & 20 & $<0.001$ \\
\hline Any leukotriene antagonist & 3 & 3 & 4 & 3 & 0.51 \\
\hline \multicolumn{6}{|l|}{ Exacerbations } \\
\hline$\geq 1$ in preceding yr (\%) & 47 & 39 & 52 & 62 & $<0.001$ \\
\hline$\geq 2$ in study yr 1 (\%) & 29 & 22 & 33 & 47 & $<0.001$ \\
\hline Rate in yr 1 (no./patient) & 1.21 & 0.85 & 1.34 & 2.00 & $<0.001$ \\
\hline Requiring hospitalization & 0.22 & 0.11 & 0.25 & 0.54 & $<0.001$ \\
\hline Requiring oral corticosteroids only & 0.14 & 0.10 & 0.15 & 0.21 & $<0.001$ \\
\hline Requiring antibiotics only & 0.44 & 0.37 & 0.46 & 0.60 & $<0.001$ \\
\hline Requiring corticosteroids and antibiotics & 0.41 & 0.27 & 0.47 & 0.65 & $<0.001$ \\
\hline
\end{tabular}

* Plus-minus values are means \pm SD unless otherwise noted. The table includes data for the 56 patients who died (from any cause) during year 1 of the study; 16 had GOLD (Global Initiative for Chronic Obstructive Lung Disease) stage 2 COPD, 26 had GOLD stage 3 , and 14 had GOLD stage 4. FEV 1 denotes forced expiratory volume in 1 second, and FVC forced vital capacity.

$\uparrow$ The body-mass index is the weight in kilograms divided by the square of the height in meters.

7 The BODE index takes into account body-mass index, airway obstruction (as assessed on the basis of $\mathrm{FEV}_{1}$ ), dyspnea (as measured with the Medical Research Council [MRC] dyspnea scale), and exercise tolerance (as measured by a 6-minute walk test); scores range from 0 to 10.

The Center for Epidemiologic Studies (CES) depression scale ranges from 0 to 60, with higher scores indicating more severe depression.

The Functional Assessment of Chronic Illness Therapy (FACIT) fatigue scale ranges from 0 (most severe fatigue) to 52 (least severe fatigue).

Scores on the St. George's Respiratory Questionnaire (SGRQ) range from 0 (good health status) to 100 (poor health status). The MRC dyspnea scale ranges from 0 (no dyspnea) to 4 (indicating that the patient is too breathless to leave home or becomes breathless when dressing or undressing) (a score of 4 indicates a minimally important clinical difference).

$\int$ The extent of disease was evaluated by a radiologist.

q Information on medication was self-reported; patients may have been taking more than one medication. 
scale $^{15}$ ), quality of life (St. George's Respiratory Questionnaire for patients with $\mathrm{COPD}^{16}$ ), fatigue (Functional Assessment of Chronic Illness Therapy fatigue scale ${ }^{17}$ ), and depression (Center for Epidemiologic Studies depression scale ${ }^{18}$ ).

\section{STATISTICAL ANALYSIS}

Descriptive data are reported as means $\pm S D$ or percentages, as appropriate. Comparisons between groups for descriptive summaries were performed with the use of analysis of variance. The incidence of exacerbations was summarized as a per-person per-year rate. Differences in exacerbations between groups were analyzed with the use of a nonparametric Kruskal-Wallis test. In the initial exploration of data, exacerbations were analyzed as an indicator variable (a patient did have or did not have an exacerbation during year 1) fitting univariate models with the use of logistic regression.

Multinomial logistic regression was performed with the use of PROC CATMOD in SAS, with the frequency of exacerbations during year 1 classified as none, one, or two or more to more fully characterize the associations between selected baseline factors and exacerbation frequency. We defined frequent exacerbations as two or more exacerbations in a year because this definition coincides with current health care utilization criteria for frequent exacerbations. For the multivariate analyses, a stepwise approach was used. All variables that were explored in the univariate analyses were considered in the multivariate model, with age, sex, smoking status, and body-mass index included as covariates in all models. A conservative significance threshold of 0.01 was used to determine the qualification of data for entry into or deletion from the model. All reported $P$ values are nominal and two-sided and were not adjusted for multiple comparisons. Stepwise logistic regression was used for analyses involving patients with very severe COPD (GOLD stage 4). Biomarker data were $\log _{10}$-transformed before all regression analyses. All patients who underwent at least 30 days of follow-up were included in the regression analyses.

\section{RESULTS}

\section{CHARACTERISTICS OF THE PATIENTS}

A total of 2164 patients were recruited for the study, and 2138 patients were enrolled and observed during follow-up. The baseline character-

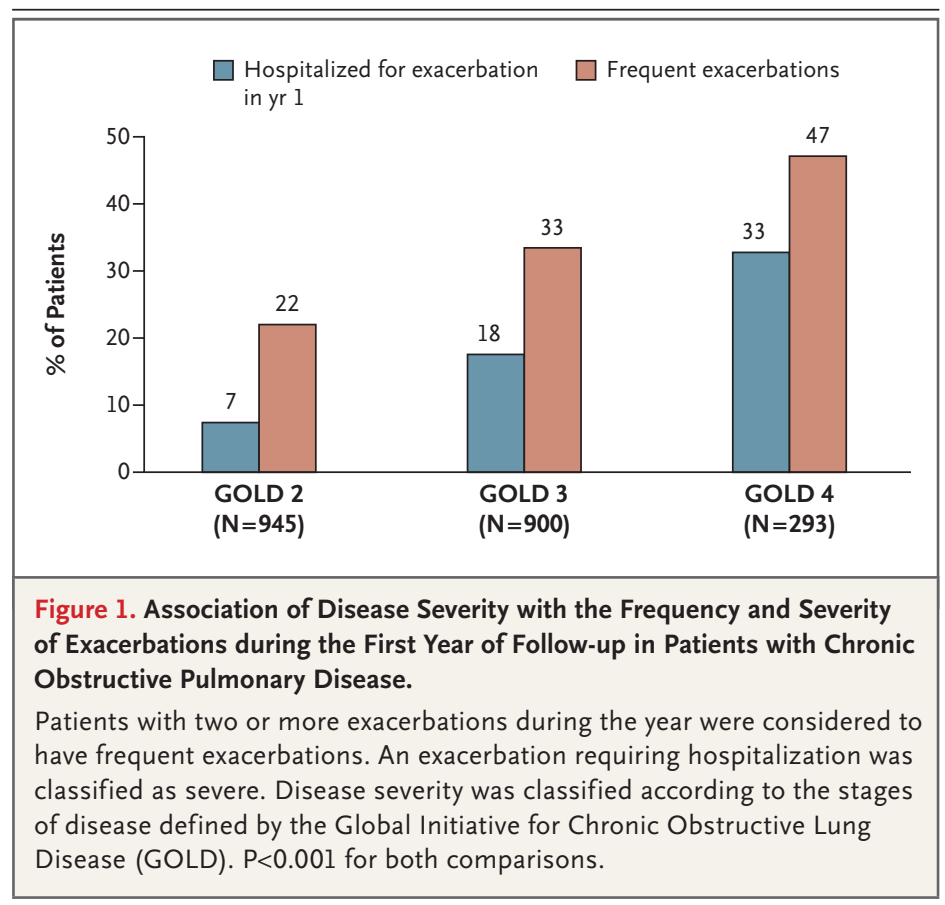

istics of the patients are reported in Table 1, categorized according to the severity of COPD. As the severity increased, exacerbations were both more frequent and more severe (Fig. 1). In the first year of follow-up, the exacerbation rates were 0.85 per person for patients with moderate disease (GOLD stage 2), 1.34 for those with severe disease (GOLD stage 3), and 2.00 for those with very severe disease (GOLD stage 4). The severity of disease also affected hospitalization in year 1 , with the proportion of patients who were hospitalized increasing with the severity of disease: GOLD stage 2, 7\%; GOLD stage 3,18\%; and GOLD stage $4,33 \%$.

\section{FACTORS ASSOCIATED WITH EXACERBATIONS}

In univariate logistic-regression analysis, we assessed factors associated with at least one exacerbation during the first year of follow-up, using all available baseline assessments in the whole cohort. The best predictor of an exacerbation in the first year was a treated exacerbation in the year before study entry (odds ratio, 4.30; 95\% confidence interval $[\mathrm{CI}], 3.58$ to 5.17 ; $\mathrm{P}<0.001)$. Other variables significantly associated with exacerbations are shown in Table 2.

Factors that were independently associated with exacerbations during the first year of follow-up, on the basis of a multinomial regression model, 


\begin{tabular}{|c|c|c|}
\hline Baseline Characteristics & Odds Ratio (95\% Wald CI) & P Value \\
\hline \multicolumn{3}{|l|}{ Demographic and clinical characteristics } \\
\hline Self-reported exacerbation during preceding yr - yes vs. no & $4.30(3.58-5.17)$ & $<0.001$ \\
\hline BODE index - per increase of 1 point & $1.23(1.18-1.28)$ & $<0.001$ \\
\hline MRC dyspnea score $-2,3$, or 4 vs. 0 or 1 & $1.83(1.54-2.18)$ & $<0.001$ \\
\hline Distance walked in $6 \mathrm{~min}-$ per decrease of $50 \mathrm{~m}$ & $1.12(1.08-1.16)$ & $<0.001$ \\
\hline Post-secondary (or higher) education level - yes vs. no & $0.70(0.58-0.83)$ & $<0.001$ \\
\hline Fat-free mass index — per increase of 1 point & $0.93(0.90-0.97)$ & $<0.001$ \\
\hline Sex - female vs. male & $1.42(1.19-1.71)$ & $<0.001$ \\
\hline Body-mass index - per increase of 1 point & $0.98(0.97-1.00)$ & 0.03 \\
\hline Age - per 10-year increase & $1.14(1.01-1.28)$ & 0.04 \\
\hline Smoking status - current vs. former smoker & $0.83(0.70-0.99)$ & 0.04 \\
\hline \multicolumn{3}{|l|}{ Lung function } \\
\hline $\mathrm{FEV}_{1}-$ per $100-\mathrm{ml}$ decrease & $1.11(1.10-1.14)$ & $<0.001$ \\
\hline $\mathrm{FEV}_{1}-$ per $5 \%$ decrease in $\%$ of predicted value & $1.15(1.11-1.18)$ & $<0.001$ \\
\hline GOLD stage - per increase to next stage & $1.74(1.53-1.97)$ & $<0.001$ \\
\hline $\mathrm{FEV}_{1}: \mathrm{FVC}-$ per $1 \%$ decrease & $1.03(1.02-1.04)$ & $<0.001$ \\
\hline FVC - per 100-ml decrease & $1.04(1.03-1.05)$ & $<0.001$ \\
\hline \multicolumn{3}{|l|}{ Emphysema } \\
\hline Per $5 \%$ increase in low-attenuation areas & $1.16(1.11-1.20)$ & $<0.001$ \\
\hline Radiologic score $>5 \%$ - yes vs. no & $1.79(1.45-2.21)$ & $<0.001$ \\
\hline \multicolumn{3}{|l|}{ Patient-reported outcomes } \\
\hline SGRQ score for COPD — per 4-point worsening & $1.10(1.08-1.12)$ & $<0.001$ \\
\hline FACIT score for fatigue - per l-point worsening & $1.03(1.02-1.04)$ & $<0.001$ \\
\hline CES score for depression - per 1-point worsening & $1.03(1.02-1.04)$ & $<0.001$ \\
\hline \multicolumn{3}{|l|}{ Laboratory values } \\
\hline Platelet count — per increase of $10 \times 10^{3} / \mathrm{mm}^{3}$ & $1.02(1.01-1.04)$ & $<0.001$ \\
\hline White-cell count - per increase of $1 \times 10^{3} / \mathrm{mm}^{3}$ & $1.07(1.03-1.12)$ & $<0.001$ \\
\hline Neutrophil count - per increase of $1 \times 10^{3} / \mathrm{mm}^{3}$ & $1.02(1.01-1.03)$ & $<0.001$ \\
\hline \multicolumn{3}{|l|}{ Biomarkers } \\
\hline Fibrinogen - mg/dl & $1.35(1.22-1.49)$ & $<0.001$ \\
\hline High-sensitivity C-reactive protein — mg/liter & $1.24(1.13-1.37)$ & $<0.001$ \\
\hline Chemokine ligand $18-\mathrm{ng} / \mathrm{ml}$ & $1.13(1.02-1.25)$ & 0.02 \\
\hline Surfactant protein $\mathrm{D}-\mathrm{ng} / \mathrm{ml}$ & $1.10(1.01-1.20)$ & 0.04 \\
\hline \multicolumn{3}{|l|}{ Self-reported symptoms and disease history - yes vs. not } \\
\hline Gastroesophageal reflux or heartburn & $1.69(1.38-2.06)$ & $<0.001$ \\
\hline Wheezing & $1.56(1.31-1.86)$ & $<0.001$ \\
\hline Osteoporosis & $1.74(1.34-2.27)$ & $<0.001$ \\
\hline Asthma & $1.52(1.23-1.87)$ & $<0.001$ \\
\hline Chronic cough & $1.20(1.01-1.42)$ & 0.04 \\
\hline
\end{tabular}

* The full version of this table, including all baseline characteristics, is available in the Supplementary Appendix. Only significant variables are listed. Nonsignificant variables included other clinical data (number of pack-years of smoking), other laboratory values (percentage of blood eosinophils and hemoglobin), other biomarker data (interleukin-6, interleukin-8, Clara cell protein-16, and tumor necrosis factor $\alpha$ ), and other data on self-reported symptoms and disease history (hypertension, hay fever, chronic bronchitis or chronic phlegm production, "lung trouble" before 16 years of age, exposure to chemical fumes or dusts at work, and cardiovascular and sinus disease). BODE denotes body-mass index, (airway) obstruction, dyspnea, and exercise tolerance; CES Center for Epidemiologic Studies; FACIT Functional Assessment of Chronic

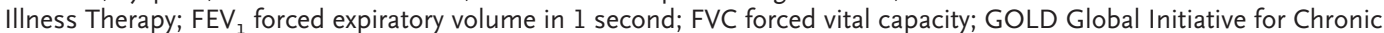
Obstructive Lung Disease; MRC Medical Research Council; and SGRQ St. George's Respiratory Questionnaire.

$\dagger$ The increment for biomarker changes was I SD on the log scale.

Data on self-reported history are based on subjects' responses to the ATS-DLD questionnaire. 


\begin{tabular}{|c|c|c|c|c|c|c|c|}
\hline \multirow[t]{3}{*}{ Factor } & \multicolumn{6}{|c|}{ Number of Exacerbations } & \multirow[t]{3}{*}{$\begin{array}{l}\text { P Value for } \\
\text { Overall Model }\end{array}$} \\
\hline & \multicolumn{2}{|l|}{$\geq 2$ vs. 0} & \multicolumn{2}{|l|}{1 vs. 0} & \multicolumn{2}{|l|}{$\geq 2$ vs. 1} & \\
\hline & $\begin{array}{l}\text { odds ratio } \\
(95 \% \mathrm{CI})\end{array}$ & Pvalue & $\begin{array}{l}\text { odds ratio } \\
(95 \% \mathrm{Cl})\end{array}$ & Pvalue & $\begin{array}{l}\text { odds ratio } \\
(95 \% \mathrm{Cl})\end{array}$ & Pvalue & \\
\hline $\begin{array}{l}\text { Exacerbation during previous yr - } \\
\text { any vs. none }\end{array}$ & $5.72(4.47-7.31)$ & $<0.001$ & $2.24(1.77-2.84)$ & $<0.001$ & $2.55(1.96-3.31)$ & $<0.001$ & $<0.001$ \\
\hline $\mathrm{FEV}_{1}$ - per $100-\mathrm{ml}$ decrease & $1.11(1.08-1.14)$ & $<0.001$ & $1.06(1.03-1.08)$ & $<0.001$ & $1.05(1.02-1.09)$ & $<0.001$ & $<0.001$ \\
\hline $\begin{array}{l}\text { SGRQ score for COPD - per } \\
\text { increase of } 4 \text { points }\end{array}$ & $1.07(1.04-1.10)$ & $<0.001$ & $1.01(0.99-1.04)$ & 0.38 & $1.06(1.03-1.09)$ & $<0.001$ & $<0.001$ \\
\hline $\begin{array}{l}\text { History of reflux or heartburn - } \\
\text { yes vs. no }\end{array}$ & $2.07(1.58-2.72)$ & $<0.001$ & $1.61(1.23-2.10)$ & $<0.001$ & $1.29(0.97-1.70)$ & $<0.005$ & $<0.001$ \\
\hline $\begin{array}{l}\text { White-cell count - per increase } \\
\text { of } 1 \times 10^{3} / \mathrm{mm}^{3}\end{array}$ & $1.08(1.03-1.14)$ & 0.002 & $1.02(0.97-1.08)$ & 0.45 & $1.06(1.01-1.12)$ & $<0.001$ & 0.007 \\
\hline
\end{tabular}

* FEV 1 denotes forced expiratory volume in 1 second, and SGRQ St. George's Respiratory Questionnaire.

are shown in Table 3. Exacerbations were significantly associated with worsening lung function (according to post-bronchodilator $\mathrm{FEV}_{1}$ ), greater impairment in health status (quality of life), a history of gastroesophageal reflux, and an increased white-cell count.

\section{STABILITY OF THE FREQUENT-EXACERBATION PHENOTYPE}

To assess the stability of the frequent-exacerbation phenotype over time, we first assessed how well patients' recall of treated exacerbations in the year before study entry predicted the number of exacerbations in year 1 , calculating positive predictive values and negative predictive values. These analyses included data from the 1679 patients who completed all 3 years of the study.

Among the 1318 patients reporting no exacerbation or one exacerbation in the year before enrollment (infrequent exacerbations), 1037 also had infrequent exacerbations in the first year of the study (negative predictive value, $79 \%$ ). Among the 361 patients reporting two or more exacerbations in the year before enrollment (frequent exacerbations), 211 also had frequent exacerbations in the first year of the study (positive predictive value, $58 \%$ ); 289 of these patients ( $80 \%$ ) had at least one exacerbation. Previous exacerbation frequency as recalled by patients therefore had a sensitivity of $43 \%$ and a specificity of $87 \%$ for actual exacerbation frequency in the following year.

We next examined the stability of exacerbation frequency between study years 1 and 2. Among the 1187 patients with infrequent exacerbations during year 1, a total of 987 had infrequent exacerbations in year 2 (negative predictive value, $83 \%$ ). Among the 492 patients with frequent exacerbations in year 1 , there were 296 who had frequent exacerbations in year 2 (positive predictive value, $60 \%$ ); $84 \%$ of patients with frequent exacerbations in year 1 had at least one exacerbation in year 2. Thus, exacerbation frequency in the first year had a sensitivity of $60 \%$ and a specificity of $83 \%$ for the frequency in the second year.

Among the 1183 patients with infrequent exacerbations in year 2 of the study, 994 also had infrequent exacerbations in year 3 (negative predictive value, 84\%). Among the 496 patients with frequent exacerbations in year 2, there were 276 who had frequent exacerbations in year 3 (positive predictive value, $56 \%$ ).

Over the three-year study period, the phenotypes for exacerbation susceptibility and resistance became stronger. Among 296 patients who had frequent exacerbations in years 1 and 2, there were $210(71 \%)$ who went on to have frequent exacerbations in year 3, and among 521 patients with no exacerbation in year 1 or year 2 , a total of 388 (74\%) also had no exacerbation in year 3. The stability of exacerbation frequency is shown in Figure 2.

\section{EXACERBATION FREQUENCY ACCORDING TO DISEASE SEVERITY}

Among the 945 patients with moderate COPD, 208 (22\%) had frequent exacerbations (two or more during the first year of the study). (The characteristics of patients with moderate COPD are listed 
according to exacerbation frequency in Table 1 in the Supplementary Appendix.) To further characterize patients with moderate COPD who had the frequent-exacerbation phenotype, we repeated the stepwise multinomial regression analysis, this time including only these patients. Because there was a high degree of confounding with sex in this model, associations were explored for each sex separately. The results are reported in Table 4. Exacerbations were significantly more common in women with moderate COPD than in men with moderate COPD: 1.02 versus 0.74 exacerbations per person per year $(\mathrm{P}<0.001)$. As in the full cohort, among both men and women, the variable most strongly associated with exacerbations during the first year of follow-up was a history of exacerbations. A greater impairment in health status (quality of life) was associated with exacerbations in the overall cohort of patients with moderate COPD, but the association was not observed in the models in which each sex was analyzed separately.

Among the 293 patients in the study who had very severe COPD, 138 (47\%) had frequent exacerbations (two or more) during the first year of the study, and 84 (29\%) had no exacerbations. (The characteristics of patients with very severe COPD, categorized according to exacerbation frequency, are listed in Table 2 in the Supplementary Appendix.) In a stepwise logistic-regression analysis, the patients with very severe COPD who did not have exacerbations during the 3-year study period were those who did not have exacerbations in the year before study entry (odds ratio, 4.53; $95 \%$ CI, 2.62 to 7.82; $\mathrm{P}<0.001$ ). No other variables were significantly associated with exacerbations, and in this group of patients, there was no association between exacerbation frequency and health status (as assessed with the use of the St. George's Respiratory Questionnaire). (The characteristics of patients with severe COPD, categorized according to exacerbation frequency, are listed in Tables 3 and 4 in the Supplementary Appendix).

DISCUSSION

Using data from the large observational ECLIPSE cohort, we examined the frequency of exacerbations among patients with moderate, severe, or very severe COPD. We found that one group of patients appeared to be susceptible to exacerbations, irrespective of disease severity as defined by spiro- metric assessment of lung function. This phenotype of susceptibility to exacerbations could be identified by asking patients about previous exacerbations and was relatively stable over a 3-year period.

A range of variables have inconsistently been associated with exacerbation frequency in previous studies. ${ }^{8-10}$ We have provided robust data from a single study showing that exacerbations requiring treatment become more frequent as the severity of COPD increases. Our study concerns moderate and severe exacerbations, which are the most burdensome to patients and health care services, among patients with a wide spectrum of COPD severity and in whom the underlying disease has been comprehensively assessed. Our conservative definition of exacerbation probably underestimates the frequency of symptom-defined events. ${ }^{8}$ Nevertheless, the proportion of patients with GOLD stage 4 disease who had frequent exacerbations (two or more annually) was more than twice the proportion of patients with GOLD stage 2 disease who had frequent exacerbations. Our data also support the view that the consequences of exacerbation become more severe with increasing disease severity. However, differentiating the severity of exacerbations from the severity of the underlying disease is complex.

The major determinant of frequent exacerbations in all GOLD stages of COPD severity that we examined was a history of exacerbations. Our results suggest that COPD with frequent exacerbations is a distinct phenotype that is seen in moderate and severe stages of disease and that the incidence of frequent exacerbations increases with increasing disease severity. We use the term "distinct" in reference to a subgroup of patients who appear to be particularly susceptible to these events, accepting that exacerbation frequency is a continuous variable. There is currently much interest in defining specific phenotypes in COPD that may have different prognoses or treatment requirements. ${ }^{19}$ Our data suggest that the frequentexacerbation phenotype can be identified on the basis of a history of exacerbations, potentially allowing for appropriate targeting of patients for interventions and making it possible to selectively recruit patients for clinical trials. Status with respect to exacerbation frequency appears to be relatively stable over time, especially in the case of patients who do not have exacerbations. This suggests that the phenotype of frequent ex- 


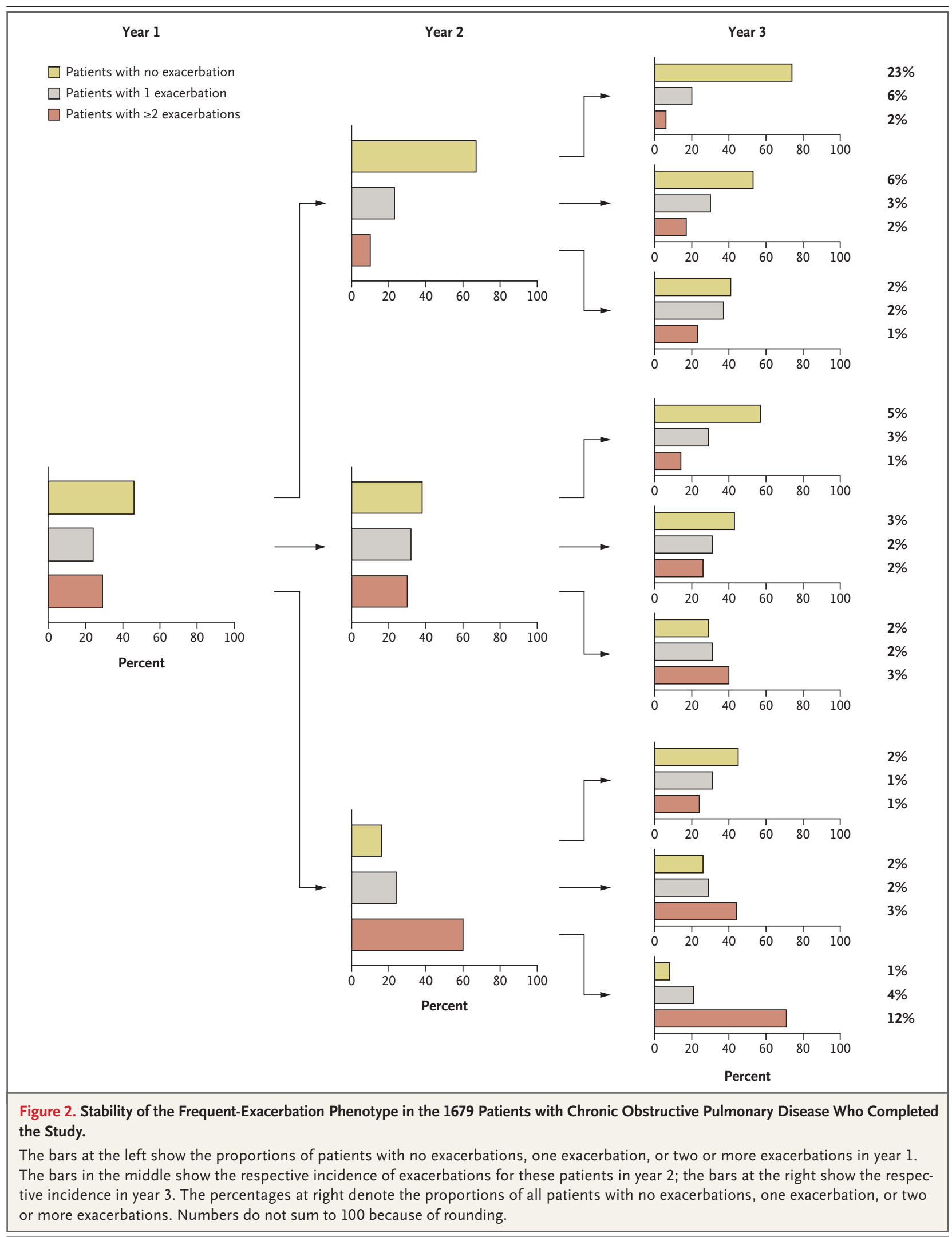

N ENGLJ MED 363;12 NEJM.ORG SEPTEMBER 16, 2010

The New England Journal of Medicine 


\begin{tabular}{|c|c|c|c|c|c|c|c|}
\hline \multirow[t]{3}{*}{ Factor } & \multicolumn{6}{|c|}{ Number of Exacerbations } & \multirow[t]{3}{*}{$\begin{array}{l}\text { Overall } \\
\text { P Value }\end{array}$} \\
\hline & \multicolumn{2}{|l|}{$\geq 2$ vs. 0} & \multicolumn{2}{|l|}{1 vs. 0} & \multicolumn{2}{|l|}{$\geq 2$ vs. 1} & \\
\hline & $\begin{array}{l}\text { odds ratio } \\
(95 \% \mathrm{Cl})\end{array}$ & Pvalue & $\begin{array}{l}\text { odds ratio } \\
(95 \% \mathrm{Cl})\end{array}$ & Pvalue & $\begin{array}{l}\text { odds ratio } \\
(95 \% \mathrm{Cl})\end{array}$ & Pvalue & \\
\hline \multicolumn{8}{|l|}{ Women $(\mathrm{N}=376)$} \\
\hline $\begin{array}{l}\text { Exacerbation during previous year - } \\
\text { yes vs. no }\end{array}$ & $8.89(4.32-18.29)$ & $<0.001$ & $2.28(1.26-4.11)$ & $<0.006$ & $3.90(1.82-8.34)$ & $<0.001$ & $<0.001$ \\
\hline History of asthma - yes vs. no & $3.38(1.62-7.05)$ & $<0.001$ & $3.00(1.59-5.66)$ & $<0.001$ & $1.12(0.53-2.38)$ & 0.76 & $<0.001$ \\
\hline $\begin{array}{l}\text { Fibrinogen - per increase of I SD } \\
\text { on log scale }\end{array}$ & $1.95(1.28-2.97)$ & $<0.002$ & $1.22(0.85-1.74)$ & 0.28 & $1.60(1.03-2.49)$ & $<0.04$ & 0.008 \\
\hline \multicolumn{8}{|l|}{ Men $(N=569)$} \\
\hline $\begin{array}{l}\text { Exacerbation during previous yr - } \\
\text { yes vs. no }\end{array}$ & $7.38(4.44-12.27)$ & $<0.001$ & $3.28(2.09-5.13)$ & $<0.001$ & $2.25(1.30-3.90)$ & 0.004 & $<0.001$ \\
\hline $\mathrm{FEV}_{1}$ - per $100-\mathrm{ml}$ decrease* & $1.20(1.11-1.31)$ & $<0.001$ & $1.07(1.00-1.14)$ & $<0.05$ & $1.13(1.04-1.23)$ & $<0.006$ & $<0.001$ \\
\hline Chronic wheezing - yes vs. no & $2.56(1.55-4.23)$ & $<0.001$ & $1.40(0.89-2.18)$ & 0.14 & $1.83(1.06-3.16)$ & $<0.03$ & 0.001 \\
\hline
\end{tabular}

* $\mathrm{FEV}_{1}$ denotes forced expiratory volume in 1 second, and NS not significant.

acerbations may best be described as an exacerbation-susceptibility phenotype, in which persons with the phenotype are prone to exacerbations as a result of intrinsic susceptibility and have exacerbations on exposure to particular triggers, such as respiratory viral infection. ${ }^{20}$

In the multivariate analysis of data for the entire cohort, in addition to the association with previous exacerbations and with greater disease severity, more frequent exacerbations were associated with greater impairment in health status, a history of gastroesophageal reflux, and an elevated white-cell count. Sex was associated with exacerbation frequency, but it was confounded with other variables. It has previously been reported that patients with frequent exacerbations may have increased airway inflammation in the stable state. ${ }^{21}$ The relationship that we observed between exacerbation frequency and health status has been noted previously, ${ }^{4}$ as has the association of exacerbations with gastroesophageal reflux. ${ }^{22}$ In contrast, chronic bronchitis was not associated with exacerbations in any of our analyses, despite previous reports that cough and sputum production are related to exacerbations in COPD. ${ }^{23-25}$

Among the patients who had moderate COPD, $22 \%$ had frequent exacerbations - - an important observation, considering that such patients, who have relatively mild disease according to $\mathrm{FEV}_{1}$ criteria, may not at present be identified for interventions to reduce exacerbations. Since moderate COPD is more prevalent than very severe $\mathrm{COPD},{ }^{26}$ the overall burden of exacerbations may be greater with milder disease. In the group of patients with moderate disease in our study, exacerbations were more common among women than among men, and there were other factors that varied according to sex. The observation of sex-based differences in exacerbation frequency is intriguing, and it is not clear whether the higher rate of exacerbations among women represents a real increase in exacerbations, women's heightened awareness of symptoms, or a greater tendency on the part of women to report such changes in symptoms to a health care provider. Regarding features that could suggest airway hyperreactivity, such as wheezing or a history of asthma, bronchodilator reversibility criteria were not used as criteria for inclusion or exclusion in the ECLIPSE study. The question of whether clinically significant airway hyperresponsiveness is also a distinct phenotype in COPD requires further study.

Among the patients in the study who had very severe COPD, 29\% appeared to have had resistance to exacerbations, although some of these patients may have been unable to recognize an 
exacerbation (which may therefore not have been reported to their physician for treatment). ${ }^{4,27}$ This finding also has potential implications for therapy, in that it may not be necessary to take aggressive approaches to the prevention of exacerbations in patients with very severe COPD if they do not have a history of such events. In our study, patients with very severe disease who did not have exacerbations did not have any other characteristics distinguishing them from patients with exacerbations except for the fact that they did not report exacerbations in the preceding year.

Although exacerbation frequency was associated with health status across the GOLD stages and in patients with moderate (stage 2) disease, this was not true among patients with the most severe disease (stage 4). Whether this trend reflects the smaller number of patients with very severe disease or a survivor effect among patients with severe disease who were participating in a longitudinal study cannot be established. Another possibility is that in patients with very severe COPD, the role of exacerbations in compromising health status is less important than that of the severity of the underlying disease itself.

The main strength of this analysis is the use of a large cohort of patients with COPD and a range of disease severity. Some important negative findings deserve mention - in particular, the fact that we did not find an association between smoking status and exacerbation frequency. ${ }^{4}$ However, our cohort was not a population sample but a sample of symptomatic patients known to respiratory physicians. Controlled trials have shown that pharmacotherapy can reduce exacerbations. ${ }^{9,10}$ We did not focus on medication as a determinant of exacerbations. Evidence-based treatment of COPD often includes the use of a history of exacerbation as an indicator for starting treatment ${ }^{12}$; in an observational study, exacerbations are therefore likely to predict treatment - not vice versa.

In conclusion, our study confirms the observation that exacerbations become more frequent and more severe as the severity of underlying COPD increases and shows that the most important determinant of frequent exacerbations is a history of exacerbations. This finding supports the hypothesis that patients who are more subject to frequent exacerbations, some of whom have milder disease, have a distinct susceptibility phe- notype that is relatively stable over time and can be identified on the basis of the patient's recall of previously treated events.

Supported by grants from GlaxoSmithKline (to Drs. Vestbo, Hurst, Anzueto, Lomas, Agusti, MacNee, Calverley, Rennard, Wouters, and Wedzicha).

Dr. Vestbo reports receiving consulting fees from GlaxoSmithKline, Boehringer Ingelheim, Nycomed, Novartis, and AstraZeneca, receiving speaking fees from GlaxoSmithKline, AstraZeneca, Boehringer Ingelheim, Chiesi, Nycomed, and Talecris, and serving as chairman of the GOLD Scientific Committee; Dr. Hurst, receiving consulting fees from AstraZeneca, speaking fees from AstraZeneca, Chiesi, and Pfizer, and travel support from GlaxoSmithKline and AstraZeneca; Dr. Anzueto, consulting fees, speaking fees, and grants from GlaxoSmithKline and consulting fees and speaking fees from Dey Pharma, Pfizer, Boehringer Ingelheim, Bayer Schering Pharma, and Schering-Plough; Dr. Agusti, consulting fees from Almirall, AstraZeneca, Boehringer Ingelheim, Chiesi, GlaxoSmithKline, Novartis, Nycomed, and Roche, speaking fees from Almirall, AstraZeneca, Boehringer Ingelheim, Chiesi, Esteve, GlaxoSmithKline, Novartis, and $\mathrm{Ny}$ comed, grants from Almirall, GlaxoSmithKline, and Nycomed, and travel support from Almirall, AstraZeneca, Boehringer Ingelheim, Chiesi, GlaxoSmithKline, Novartis, and Nycomed; Dr. MacNee, consulting fees from Boehringer Ingelheim, SMB, GlaxoSmithKline, Pfizer, and AstraZeneca and speaking fees from GlaxoSmithKline and AstraZeneca; Dr. Calverley, receiving consulting fees from GlaxoSmithKline, AstraZeneca, Nycomed, and Boehringer Ingelheim, speaking fees from GlaxoSmithKline and Nycomed, and travel support from Boehringer Ingelheim and providing expert testimony for Forest and Nycomed; Dr. Rennard, receiving grants from AstraZeneca, Biomarck, Centocor, Mpex, Nabi, Novartis, and Otsuka, consulting or speaking fees from Able Associates, Adelphi Research, APT Pharma and Britnall, Aradign, AstraZeneca, Boehringer Ingelheim, Chiesi, CommonHealth, Consult Complete, COPD Forum, Data Monitor, Decision Resource, Defined Health, Dey, Dunn Group, Easton Associates, Equinox, Gerson, GlaxoSmithKline, Infomed, KOL Connection, M. Pankove, MedaCorp, MDRx Financial, Mpex, Oriel Therapeutics, Otsuka, Pennside, PharmaVentures, Pharmaxis, PriceWaterhouse, Propagate, Pulmatrix, Reckner Associates, Recruiting Resources, Roche, Schlesinger Medical, Scimed, Sudler and Hennessey, TargeGen, Theravance, UBC, Uptake Medical, and VantagePoint Management; Dr. Wouters, consulting fees from GlaxoSmithKline and Nycomed, speaking fees from GlaxoSmithKline, Nycomed, and AstraZeneca, and grants from GlaxoSmithKline and AstraZeneca; and Dr. Wedzicha, speaking fees from GlaxoSmithKline, AstraZeneca, Novartis, Bayer, Boehringer Ingelheim, Chiesi, and Respifor, grants from GlaxoSmithKline, AstraZeneca, Chiesi, and Novartis, and travel reimbursements from Boehringer Ingelheim. Drs. Müllerova, Locantore, Miller, and Tal-Singer are employees of GlaxoSmithKline and report owning stocks and shares of GlaxoSmithKline.

Disclosure forms provided by the authors are available with the full text of this article at NEJM.org.

We thank all the study participants for their willingness to advance medical science in the field of COPD, Gardiner-Caldwell Communications for technical assistance in the initial preparation of a figure, Drs. Nestor Müller and Paola Nasute Fauerbach for their radiologic expertise in the assessment of emphysema, and Dr. Harvey Coxson, Tara Candido, Sebastian Cogswell, Heather Davis, Nima Farzaneh, Lukas Holy, Natasha Krowchuk, Helena Lee, Evan Phillips, Claudine Storness-Bliss, Nerissa Tai, Anh-Toan Tran, Nghia Tran, Eugene Wang, and Tomonori Yokogawa for technical assistance with the CT analysis and data management. 


\section{APPENDIX}

Members of the ECLIPSE steering and scientific committees and the study investigators are as follows. Steering Committee: H. Coxson, L. Edwards, R. Tal-Singer, D. Lomas, W. MacNee, E. Silverman, C. Crim, J. Vestbo, J. Yates. Scientific Committee: A. Agusti, P. Calverley, B. Celli, C. Crim, B. Miller, W. MacNee, S. Rennard, R. Tal-Singer, E. Wouters, J. Yates. Investigators — Bulgaria: Y. Ivanov, Pleven; K. Kostov, Sofia. Canada: J. Bourbeau, Montreal; M. Fitzgerald, Vancouver, BC; P. Hernandez, Halifax, NS; K. Killian, Hamilton, ON; R. Levy, Vancouver, BC; F. Maltais, Montreal; D. O’Donnell, Kingston, ON. Czech Republic: J. Krepelka, Prague. Denmark: J. Vestbo, Hvidovre. The Netherlands: E. Wouters, Horn-Maastricht. New Zealand: D. Quinn, Wellington. Norway: P. Bakke, Bergen. Slovenia: M. Kosnik, Golnik. Spain: A. Agusti, J. Sauleda, P. de Mallorca. Ukraine: Y. Feschenko, V. Gavrisyuk, L. Yashina, Kiev; N. Monogarova, Donetsk. United Kingdom: P. Calverley, Liverpool; D. Lomas, Cambridge; W. MacNee, Edinburgh; D. Singh, Manchester; J. Wedzicha, London. United States: A. Anzueto, San Antonio, TX; S. Braman, Providence, RI; R. Casaburi, Torrance CA; B. Celli, Boston; G. Giessel, Richmond, VA; M. Gotfried, Phoenix, AZ; G. Greenwald, Rancho Mirage, CA; N. Hanania, Houston; D. Mahler, Lebanon, NH; B. Make, Denver; S. Rennard, Omaha, NE; C. Rochester, New Haven, CT; P. Scanlon, Rochester, MN; D. Schuller, Omaha, NE; F. Sciurba, Pittsburgh; A. Sharafkhaneh, Houston; T. Siler, St. Charles, MO; E. Silverman, Boston; A. Wanner, Miami; R. Wise, Baltimore; R. ZuWallack, Hartford, CT.

\section{REFERENCES}

1. Kanner RE, Anthonisen NR, Connett JE. Lower respiratory illnesses promote $\mathrm{FEV}_{1}$ decline in current smokers but not ex-smokers with mild chronic obstructive pulmonary disease: results from the Lung Health Study. Am J Respir Crit Care Med 2001;164:358-64.

2. Donaldson GC, Seemungal TAR, Bhowmik A, Wedzicha JA. Relationship between exacerbation frequency and lung function decline in chronic obstructive pulmonary disease. Thorax 2002;57:84752. [Erratum, Thorax 2008;63:753.]

3. Donaldson GC, Wilkinson TMA, Hurst JR, Perera WR, Wedzicha JA. Exacerbations and time spent outdoors in chronic obstructive pulmonary disease. Am J Respir Crit Care Med 2005;171:446-52.

4. Seemungal TA, Donaldson GC, Paul EA, Bestall JC, Jeffries DJ, Wedzicha JA. Effect of exacerbation on quality of life in patients with chronic obstructive pulmonary disease. Am J Respir Crit Care Med 1998;157:1418-22.

5. Soler-Cataluña JJ, Martínez-García MÁ, Román Sánchez P, Salcedo E, Navarro $\mathrm{M}$, Ochando $\mathrm{R}$. Severe acute exacerbations and mortality in patients with chronic obstructive pulmonary disease. Thorax 2005;60:925-31.

6. Sullivan SD, Ramsey SD, Lee TA. The economic burden of COPD. Chest 2000; 117:Suppl:5S-9S.

7. Celli BR, MacNee W. Standards for the diagnosis and treatment of patients with COPD: a summary of the ATS/ERS position paper. Eur Respir J 2004;23:932-46.

8. Donaldson GC, Wedzicha JA. COPD exacerbations. 1: Epidemiology. Thorax 2006;61:164-8.

9. Calverley PM, Anderson JA, Celli B, et al. Salmeterol and fluticasone propionate and survival in chronic obstructive pulmonary disease. N Engl J Med 2007;356:77589.
10. Tashkin DP, Celli B, Senn S, et al. A 4-year trial of tiotropium in chronic obstructive pulmonary disease. $\mathrm{N}$ Engl J Med 2008;359:1543-54.

11. Vestbo J, Anderson W, Coxson HO, et al. Evaluation of COPD Longitudinally to Identify Predictive Surrogate End-points (ECLIPSE). Eur Respir J 2008;31:869-73.

12. Global Initiative for Chronic Obstructive Lung Disease. Global strategy for the diagnosis, management, and prevention of chronic obstructive lung disease. (Accessed August 23, 2010, at http://www .goldcopd.org/Guidelineitem.asp?11=2\& 12=1\&intId=2180.)

13. Comstock GW, Tockman MS, Helsing KJ, Hennesy KM. Standardized respiratory questionnaires: comparison of the old with the new. Am Rev Respir Dis 1979; 119:45-53.

14. Wedzicha JA, Seemungal TA. COPD exacerbations: defining their cause and prevention. Lancet 2007;370:786-96.

15. Bestall JC, Paul EA, Garrod R, Garnham $\mathrm{R}$, Jones PW, Wedzicha JA. Usefulness of the Medical Research Council (MRC) dyspnoea scale as a measure of disability in patients with chronic obstructive pulmonary disease. Thorax 1999;54:581-6.

16. Meguro M, Barley EA, Spencer S, Jones PW. Development and validation of an improved, COPD-specific version of the St. George Respiratory Questionnaire. Chest 2007;132:456-63.

17. Cella D, Lai JS, Chang CH, Peterman A Slavin M. Fatigue in cancer patients compared with fatigue in the general United States population. Cancer 2002;94:52838.

18. Radloff L. The CES-D Scale: a self-report depression scale for research in the general population. Appl Psychol Meas 1977;1:385-401.

19. Han MK, Agusti A, Calverley PM, et al. COPD phenotypes: the future of COPD.
Am J Respir Crit Care Med 2010 June 2 (Epub ahead of print).

20. Seemungal T, Harper-Owen R, Bhowmik A, et al. Respiratory viruses, symptoms, and inflammatory markers in acute exacerbations and stable chronic obstructive pulmonary disease. Am J Respir Crit Care Med 2001;164:1618-23.

21. Bhowmik A, Seemungal TA, Sapsford RJ, Wedzicha JA. Relation of sputum inflammatory markers to symptoms and lung function changes in COPD exacerbations. Thorax 2000;55:114-20.

22. Rascon-Aguilar IE, Pamer M, Wludyka $\mathrm{P}$, et al. Role of gastroesophageal reflux symptoms in exacerbations of COPD. Chest 2006;130:1096-101.

23. Miravitlles M, Guerrero T, Mayordomo C, Sánchez-Aqudo L, Nicolau F, Seqú JL. Factors associated with increased risk of exacerbation and hospital admission in a cohort of ambulatory COPD patients: a multiple logistic regression analysis. Respiration 2000;67:495-501.

24. Foreman MG, DeMeo DL, Hersh CP, Reilly JJ, Silverman EK. Clinical determinants of exacerbations in severe, earlyonset COPD. Eur Respir J 2007;30:1124-30. 25. Burgel PR, Nesme-Meyer P, Chanez P, et al. Cough and sputum production are associated with frequent exacerbations and hospitalizations in COPD subjects. Chest 2009;135:975-82.

26. Shahab L, Jarvis MJ, Britton J, West R. Prevalence, diagnosis and relation to tobacco dependence of chronic obstructive pulmonary disease in a nationally representative population sample. Thorax 2006; 61:1043-7.

27. Langsetmo L, Platt RW, Ernst P, Bourbeau J. Underreporting exacerbation of chronic obstructive pulmonary disease in a longitudinal cohort. Am J Respir Crit Care Med 2008;177:396-401.

Copyright (C) 2010 Massachusetts Medical Society. 